\title{
Relaxation dynamics of carboxylated nitrile rubber filled with organomodified nanoclay
}

\author{
J. Fritzsche', A. Das ${ }^{2}$, R. Jurk², K. W. Stöckelhuber², G. Heinrich², M. Klüppel ${ }^{*}$ \\ ${ }^{1}$ Deutsches Institut für Kautschuktechnologie e.V., Eupener Straße 33, D-30519 Hannover, Germany \\ ${ }^{2}$ Leibniz-Institut für Polymerforschung Dresden e.V., Hohe Straße 6, D-01069 Dresden, Germany
}

Received 28 January 2008; accepted in revised form 3 April 2008

\begin{abstract}
In order to improve the physical properties of elastomers and to get more insight into the polymer dynamics close to filler interphases a carboxylated nitrile rubber (XNBR) was filled with up to $10 \mathrm{phr}$ of layered silicate and investigated by dielectric and dynamic-mechanical analysis as well as by IR spectroscopy. Three relaxation processes have been detected beside the electrode polarization effect obtained in dielectric measurements. The relaxation process at low temperatures can be assigned to the $\beta$-process due to the rotational motion of side groups. Its temperature dependence follows an Arrhenius-like behaviour and there is no significant change in the shape of this process with the incorporation of filler. The glass transition at medium temperature shows a Vogel-Fulcher-dependence but seems to be independent of filler as well. At higher temperatures a new relaxation process was detected which is probably due to the formation of zinc-carboxyl-clusters. In dielectric and dynamic-mechanical measurements this process increases with increasing loading of organoclay and is shifted to higher temperature.
\end{abstract}

Keywords: nanocomposites, layered silicate, dielectric spectroscopy, relaxation dynamics, dynamic-mechanical spectroscopy

\section{Introduction}

Recently, reinforcement of polymers with nanostructured fillers became more and more important. Comparing with traditional fillers like silica and carbon black the physical properties of elastomers are improved due to the fine dispersion and pronounced flocculation of nanoscopic filler particles. However, dispersion of nano-particles in a polymer matrix can be problematic in the case of strong polar bonding between the filler particles, especially for non-polar rubbers. In particular, the application of precipitated silica in high performance tires became a successful technology only after the dispersion problem was solved by coating the silica with a bifunctional silane in a specific complicated multi-step procedure. In addition to nano-scale sil- ica the incorporation of layered silicate into the polymer matrix is a field of intensive research. In the literature an extensive variety of reports can be found describing the improvement effects concerning for instance mechanical and tribological properties [1-3] as well as thermal and chemical stability $[4,5]$. Due to the intercalation and exfoliation of organolayered silicate and consequently a large increase in the active surface of the filler the low concentration of clay is one of the most important aspects of rubber layered silicate nanocomposites. The effect of reinforcement mainly depends on the degree of dispersion of the inorganic and polar clay in the organic and in most cases non polar polymer matrix. The dispersion of these particles from its staged layer conformation with individual 
mono layer into rubber matrix with poor surface energy is experimentally difficult [6]. This factor is predominantly noticeable for the case of non polar rubber like EPDM (Ethylene Propylene Diene Rubber), NR (Natural rubber) and SBR (Styrene Butadiene Rubber). For this reason a polar rubber like carboxylated nitrile rubber was chosen for insuring a reasonable interaction between organoclay and polymer. In a separate paper we describe the physical properties, XRD-data and filler distribution of layered silicate in carboxylated nitrile rubber [17]. In this present work especially the polymer-filler interaction has been investigated using dielectric and dynamic-mechanical analysis as well as IRspectroscopy.

\section{Experimental}

\subsection{Sample preparation}

The samples have been prepared with the carboxylated nitrile rubber (Krynac 7.40, ML $1+4\left[\right.$ at $100^{\circ} \mathrm{C}$ ] $38 \pm 4$, acrylonitrile content 26.5 , carboxylic acid content 7\%, Lanxess, Germany) which was filled with different loadings, in example $0,2.5,5,7.5$ and $10 \mathrm{phr}$, of organomodified layered silicate (organomodified pristine sodium montmorillonite, Cloisite $\mathrm{Na}^{+}$(Na-MMT) Süd Chemie AG, Germany, containing quaternary ammonium salt as organic modifier, basal spacing of this organoclay is $2.98 \mathrm{~nm}$ ). $3 \mathrm{phr}$ zinc oxide, $2 \mathrm{phr}$ stearic acid, $2 \mathrm{phr}$ diphenyl-guanidine (DPG), 1,7 phr n-cyclohexyl-2-benzothiazole-sulfenamide (CBS) and $1,4 \mathrm{phr}$ soluble sulfur were used as vulcanisation system. The compounds were prepared in a laboratory size mixing mill with a friction ratio of 1:1.2 and using an internal mixer rotating at $50 \mathrm{rpm}$ during $10 \mathrm{~min}$. At first the rubber and organoclay were mixed in the internal mixer at $160^{\circ} \mathrm{C}$ and then rest of curatives was added at $40^{\circ} \mathrm{C}$ in the two-roll mill. The curing study was carried out with the help of a moving die rheometer (Scarabaeus V-50) at $160^{\circ} \mathrm{C}$. The stocks were cured under pressure at $160^{\circ} \mathrm{C}$ to $2 \mathrm{~mm}$ plates.

\subsection{Dielectric broadband spectroscopy}

Dielectric investigations have been carried out in a wide temperature range $\left(-100^{\circ} \mathrm{C}\right.$ to $\left.+150^{\circ} \mathrm{C}\right)$ and at frequencies from $0.1 \mathrm{~Hz}$ to $10 \mathrm{MHz}$ using a broad- band dielectric spectrometer BDS 40 (Novocontrol $\mathrm{GmbH}$, Germany). The temperature was varied in five degree steps using the temperature control system Novocool. The temperature uncertainty amounts to $\pm 0.5^{\circ} \mathrm{C}$.

The measured geometry was a disc shaped plate capacitor with a diameter of $40 \mathrm{~mm}$. The sample with a thickness of $2 \mathrm{~mm}$ was placed between two gold-plated electrodes. To provide a excellent contact between sample and electrodes thin gold layers have been sputtered onto the flat surface of the sample plate. The dielectric permittivity and the dielectric loss have been recorded for each sample in dependence of temperature and frequency.

\subsection{Dynamic-mechanical analysis}

The dynamic-mechanical measurements were performed in the torsion-rectangular mode with strip specimen of $2 \mathrm{~mm}$ thickness on a ARES rheometer (Rheometrix). The dynamic moduli were measured over a wide temperature range $\left(-80\right.$ to $\left.+80^{\circ} \mathrm{C}\right)$ at a frequency of $1 \mathrm{~Hz}$ and $0.5 \%$ strain amplitude.

\subsection{IR-spectroscopy}

Infrared spectroscopic studies have been carried out using a Fourier-Transform-Infrared-spectrometer (Thermo Nicolet Nexus). The spectra were obtained using the attenuated total reflectance (ATR) technique with a diamond crystal.

\subsection{TEM}

For TEM investigations ultra-thin sections were cut by microtome at about $-100^{\circ} \mathrm{C}$ and the images were taken by Libra 120 transmission electron microscope by Zeiss with an acceleration voltage of $200 \mathrm{kV}$.

\section{Results and discussion}

\subsection{Dielectric investigations}

Due to its carboxyl groups and the nitrile content the high polarity of a XNBR provides large values for the dielectric loss $\varepsilon^{\prime \prime}$. Examples of the results obtained for the dielectric loss $\varepsilon^{\prime \prime}$ in dependence of temperature and frequency for the unfilled sample and the sample filled with $10 \mathrm{phr}$ organoclay are given in Figure 1. 

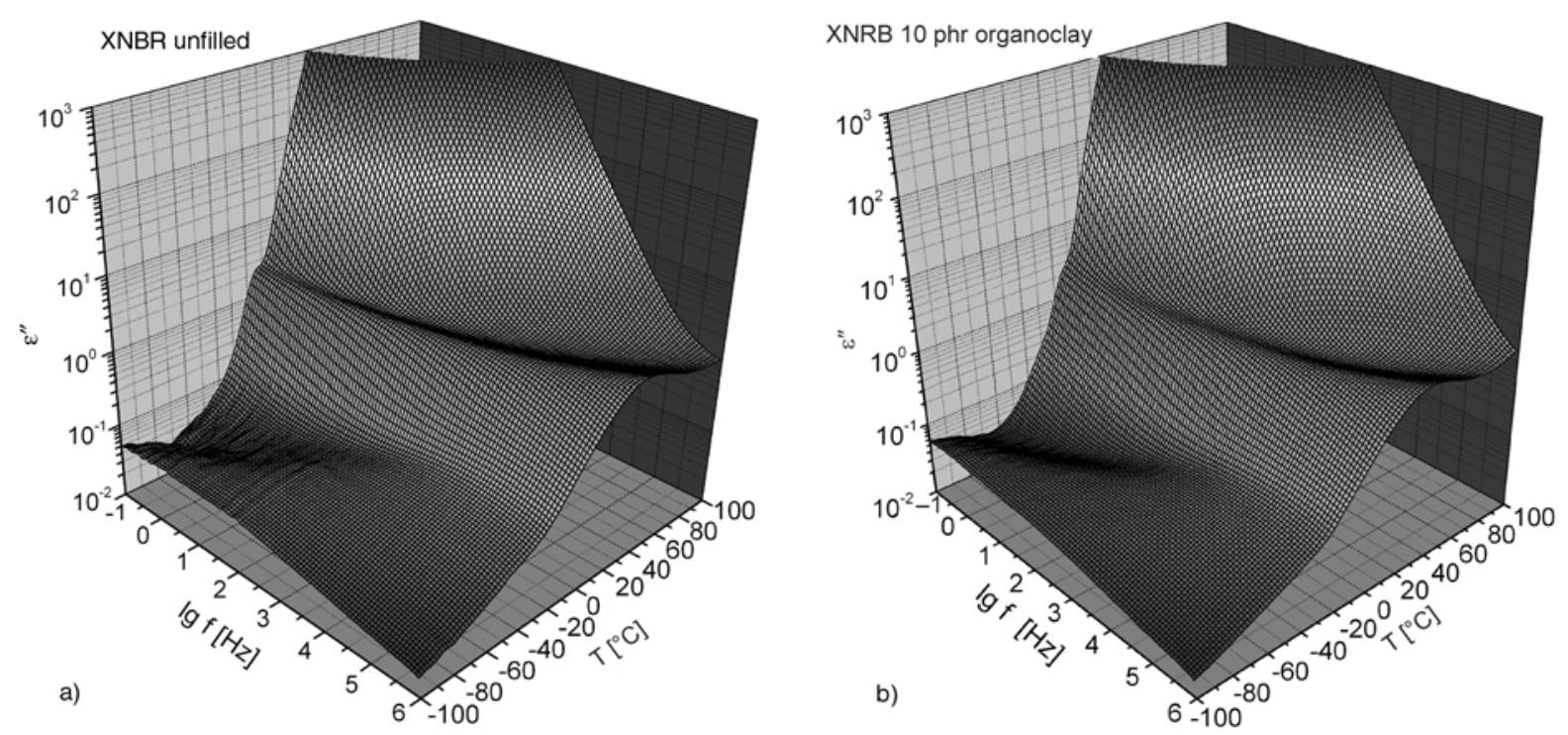

Figure 1. Dielectric loss $\varepsilon^{\prime \prime}$ in dependence of temperature an frequency for a) the unfilled sample and b) the sample filled with $10 \mathrm{phr}$ of organoclay

In all measurements the glass transition process $(\alpha-$ process ) due to the cooperative segmental motion of the chain is observable forming a characteristic temperature and frequency dependent VogelFulcher-behaviour. At low temperatures the Arrhenius-activated $\beta$-process can be observed in all samples which is due to local fluctuations of chain segments or side groups. At high temperatures the value of $\varepsilon^{\prime \prime}$ increases extremely with increasing temperatures probably due to conductivity effects or electrode polarization.

To analyze the high temperature part of the spectra the analyzing procedure developed by Steeman and van Turnhout [7] was applied to the measured data, which has been reviewed by Wübbenhorst and van Turnhout [8]. This method is based on the Kramers-Kronig-relation, one of which is Equation (1), saying that both $\varepsilon^{\prime}$ and $\varepsilon^{\prime \prime}$ carry the same information about relaxation processes and are related by a Hilbert transformation:

$$
\varepsilon^{\prime \prime}\left(\omega_{0}\right)=\frac{\sigma_{d c}}{\varepsilon_{0} \omega_{0}}+\frac{2}{\pi} \int_{0}^{\infty} \varepsilon^{\prime}(\omega) \frac{\omega_{0}}{\omega^{2}-\omega_{0}^{2}} \mathrm{~d} \omega
$$

In this procedure the derivation of $\varepsilon^{\prime}$ denoted as $\varepsilon_{\text {deriv }}^{\prime \prime}(2)$ is used in order to obtain narrow and sharp peaks and to eliminate conductivity effects due to the independence of $\varepsilon^{\prime}$ from ohmic conductivity:

$$
\varepsilon^{\prime \prime}{ }_{\text {deriv }}=-\frac{\pi}{2} \frac{\partial \varepsilon^{\prime}(\omega)}{\partial \ln \omega} \approx \varepsilon^{\prime \prime}
$$

In the case of broad relaxation peaks like those of the $\alpha$-transition, Equation (2) is almost exact and the derivative reproduces the measured frequency dependent $\varepsilon^{\prime \prime}$ data. Contrary, for narrow Debye-like processes a peak sharpening is observed and $\varepsilon_{\text {deriv }}^{\prime \prime} \sim \omega^{-2}$ is obtained for large frequencies instead of $\varepsilon^{\prime \prime} \sim \omega^{-1}$ [8]. This opens the interesting possibility to get more information about low frequency relaxation processes of dipolar origin, which are often obscured by strong electrode polarization due to ionic conduction. In the XNBR samples under consideration ionic conductance probably results from mobile protons due to the presence of carboxylic groups and other ions obtained from the addition of the processing agents zinc oxide and stearic acid. The blocking of ions at the metallic electrodes leads to the pronounced relaxation process at high temperatures and low frequencies observed in Figure 1. This electrode polarization refers typically to a sharp Debye-like processes and therefore the application of the derivative considered in Equation (2) is expected to sharpen this undesired peak. As a consequence, other processes of dipolar origin may become visible in the spectrum.

The spectrum of the XNBR sample filled with $10 \mathrm{phr}$ is shown in Figure 2 after applying the derivative method Equation (2). Interestingly, the resulting spectra now show an additional relaxation process at higher temperatures in all investigated samples, which obviously was obscured in the orig- 


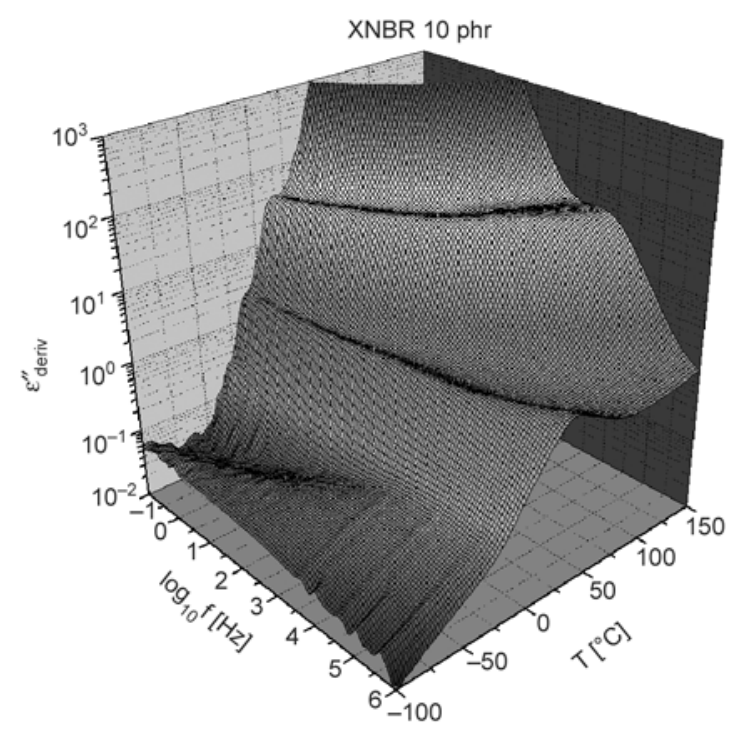

Figure 2. Representation of $\varepsilon_{\text {deriv }}^{\prime \prime}$ in dependence of temperature and frequency after applying the analyzing procedure Equation (2) for the XNBR filled with $10 \mathrm{phr}$ organoclay $[7,8]$

inal spectra by the strong electrode polarization. Though this process is still partly covered by electrode polarization its location and activation behavior can be evaluated. A plot of $\varepsilon_{\text {deriv }}^{\prime \prime}$ against temperature at $0.5 \mathrm{kHz}$ given in Figure 3 shows an increase of the dielectric loss with increasing content of organoclay. Additionally a reasonable shift to higher temperatures of this process from the unfilled sample to the filled samples is detectable. This shifting indicates the assumption of different processes in the unfilled and the filled samples.

To investigate the activation energies of these processes as well as the relaxation process parameters like dielectric strength, relaxation rate and shape parameters the obtained data have been ana-

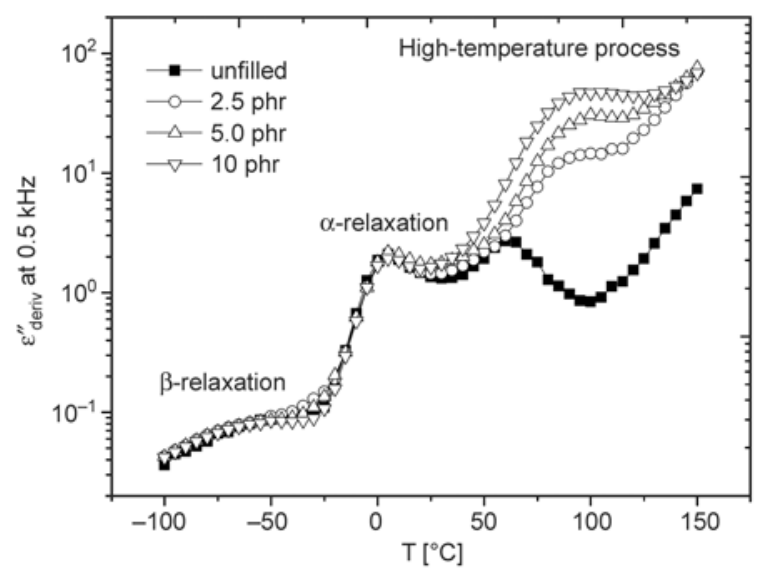

Figure 3. Plot of $\varepsilon_{\text {deriv }}^{\prime \prime}$ against temperature at $0.5 \mathrm{kHz}$ for all investigated samples lyzed using the fitting program WINFIT (Novocontrol, Germany).

The Cole-Cole-plot of dielectric loss against the dielectric permittivity shows symmetric semicircles, hence the fits have been carried out using Cole-Cole-functions (3) to describe symmetrical but broadened relaxation processes with respect to the Debye model:

$$
\varepsilon_{C C}^{*}=\varepsilon_{\infty}+\frac{\Delta \varepsilon}{1+(i \omega \tau)^{\alpha}}
$$

Here $\varepsilon_{\infty}$ describes the dielectric permittivity at infinite frequencies, $\Delta \varepsilon$ the dielectric strength and $\alpha$ the broadening parameter. The fitting procedure has been carried out for each temperature and is exemplarily shown in Figure 4 for the unfilled XNBR sample and in Figure 5 for the sample filled with $10 \mathrm{phr}$ organoclay at $298.15 \mathrm{~K}$. Obviously, the low frequency peak, corresponding to the high temperature process in Figure 3 increases significantly with the addition of organoclay and is shifted to lower frequencies. The activation diagram of all XNBR samples is shown in Figure 6. The resulting parameters are shown in Table 1.

The $\alpha$-processes have been analyzed with a VogelFulcher-Tamman equation (4) resulting in values for the apparent activation energy $E_{A}$, the relaxation rate $\lg f_{0}$ and the Vogel-temperature $T_{V F}$ :

$$
f(T)=f_{0} \exp \left(\frac{E_{A}}{k_{B}\left(T-T_{V F}\right)}\right)
$$

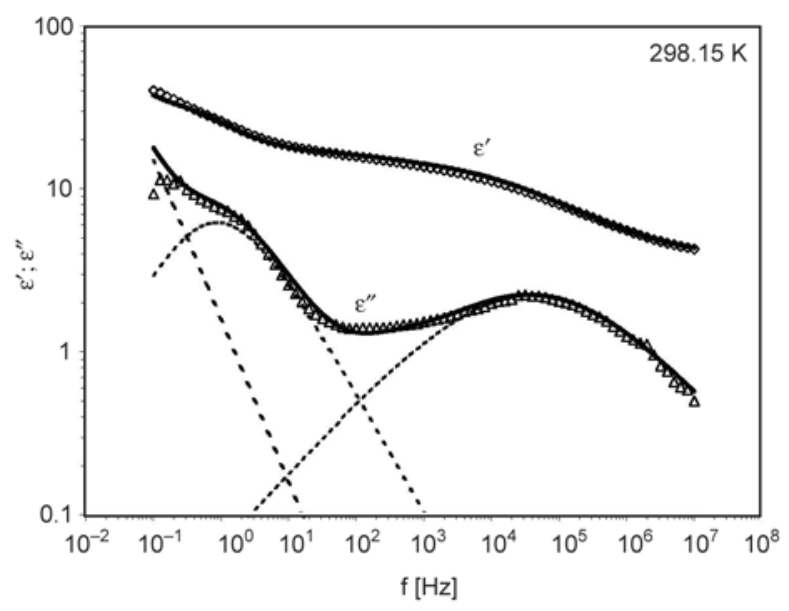

Figure 4. Fitting procedure of $\varepsilon^{\prime}$ and $\varepsilon_{\text {deriv }}^{\prime \prime}$ for the unfilled sample at 298.15 K. Symbols are experimental data, dashed lines are single Cole-Cole functions, solid lines are the resulting fit curves 


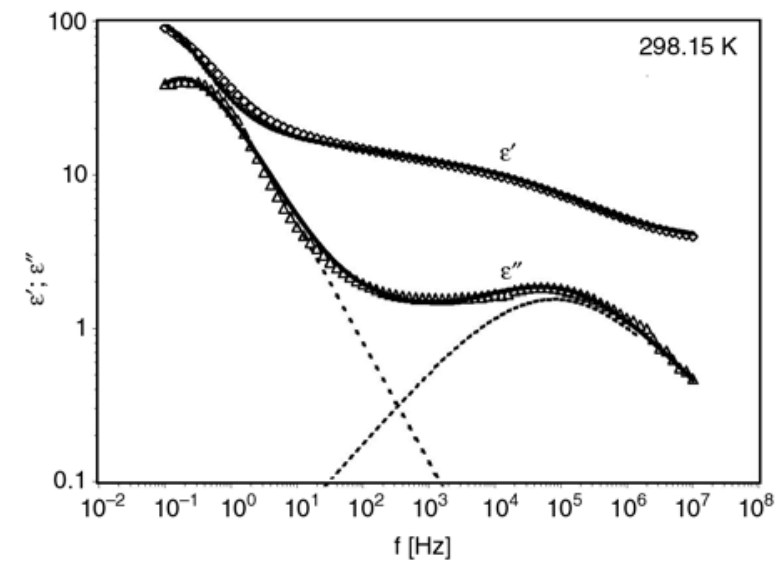

Figure 5. Fitting procedure of $\varepsilon^{\prime}$ and $\varepsilon_{\text {deriv }}^{\prime \prime}$ for the sample filled with $10 \mathrm{phr}$ organoclay at $298.15 \mathrm{~K}$. Symbols are experimental data, dashed lines are single Cole-Cole functions, solid lines are the resulting fit curves

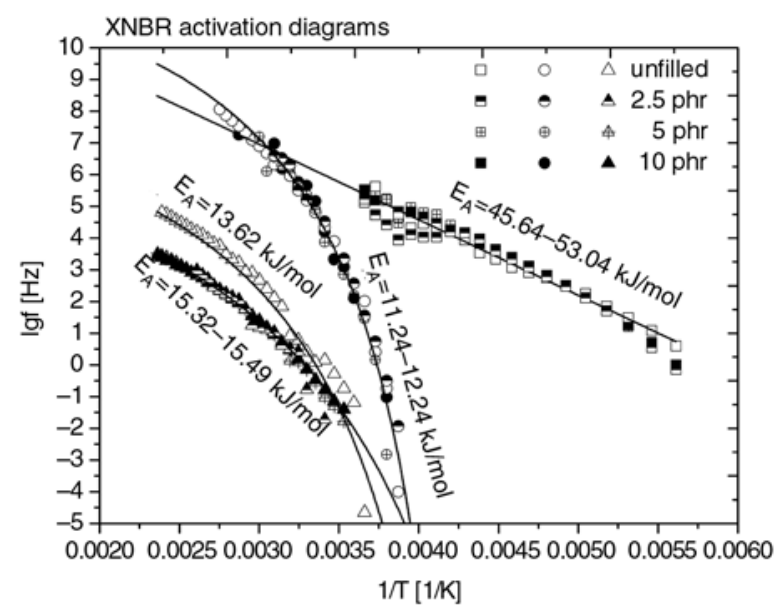

Figure 6. Activation diagram of the XNBR samples after applying the derivation procedure

Table 1. Activation parameters of the XNBR samples for the detected processes

\begin{tabular}{|l|c|c|c|c|}
\hline & unfilled & $\mathbf{2 . 5}$ phr & $\mathbf{5}$ phr & 10 phr \\
\hline \multicolumn{5}{|c|}{$\alpha$-process } \\
\hline $\lg f_{0}[\mathrm{~Hz}]$ & 12.505 & 12.505 & 12.505 & 12.505 \\
\hline$E_{A}[\mathrm{~kJ} / \mathrm{mol}]$ & 11.84 & 12.24 & 11.24 & 12.21 \\
\hline$T_{V F}[\mathrm{~K}]$ & 217.18 & 214.13 & 222.72 & 223.21 \\
\hline \multicolumn{5}{|c|}{$\beta$-process } \\
\hline $\lg f_{0}[\mathrm{~Hz}]$ & 14.12 & 14.13 & 15.88 & 15.25 \\
\hline$E_{A}[\mathrm{~kJ} / \mathrm{mol}]$ & 45.64 & 46.65 & 53.04 & 50.29 \\
\hline \multicolumn{5}{|c|}{ high-temperature process } \\
\hline $\lg f_{0}[\mathrm{~Hz}]$ & 8.18 & 7.75 & 7.08 & 6.94 \\
\hline$E_{A}[\mathrm{~kJ} / \mathrm{mol}]$ & 13.62 & 15.32 & 15.49 & 15.44 \\
\hline$T_{V F}[\mathrm{~K}]$ & 210.97 & 208.77 & 191.93 & 188.32 \\
\hline
\end{tabular}

Since the relaxation rate $f_{0}$ of the $\alpha$-process can hardly be fitted, it was set to the constant universal value $\lg f_{0}=12,5$ empirically found for diene rubbers. The activation energies are with $11-12 \mathrm{~kJ} / \mathrm{mol}$

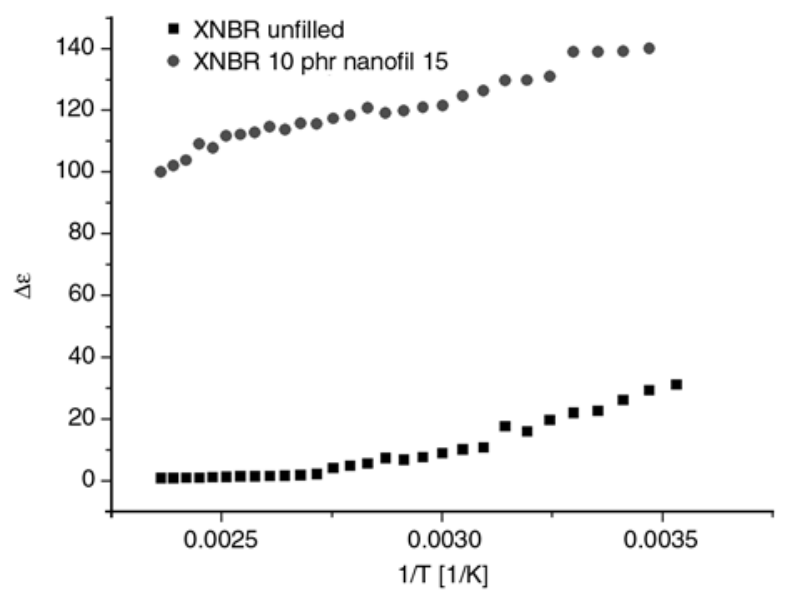

Figure 7. Relaxation strength in dependence of temperature for the high-temperature process of the unfilled sample and the sample filled with $10 \mathrm{phr}$ of organoclay

nearly equivalent. Accordingly the glass transition process seems to be independent of the incorporation of organoclay. The $\beta$-process was described by a simple Arrhenius relation. As well the activation energies of the $\beta$-process do only show small difference with $45-53 \mathrm{~kJ} / \mathrm{mol}$, here the uncertainty is much higher due to the linear behavior.

It is clearly shown that the high-temperature process can be described by the Vogel-FulcherTamman equation. Here the relaxation rate was also a fit parameter. The relaxation rate is decreasing with increasing organoclay content as well the Vogel-Temperature is decreasing. The activation energy for the unfilled sample is $13 \mathrm{~kJ} / \mathrm{mol}$, in the filled samples $15 \mathrm{~kJ} / \mathrm{mol}$. The difference is not significant, conspicuous is the very small difference among the different filled samples.

The relaxation strength of the high-temperature process investigated for the unfilled sample and the sample filled with $10 \mathrm{phr}$ of organoclay is shown in Figure 7. It is evident that the relaxation strength is extremely higher in case of the filled sample which was as well visible in Figure 3. In both cases the relaxation strength is increasing with decreasing temperature, showing the typical behavior of a dipole based process.

\subsection{Dynamic-mechanical investigations}

In dynamic-mechanical measurements the tan $\delta$ for the unfilled and filled samples are obtained and plotted against the temperature in Figure 8. The glass transition process is detectable at $-10^{\circ} \mathrm{C}$ and 


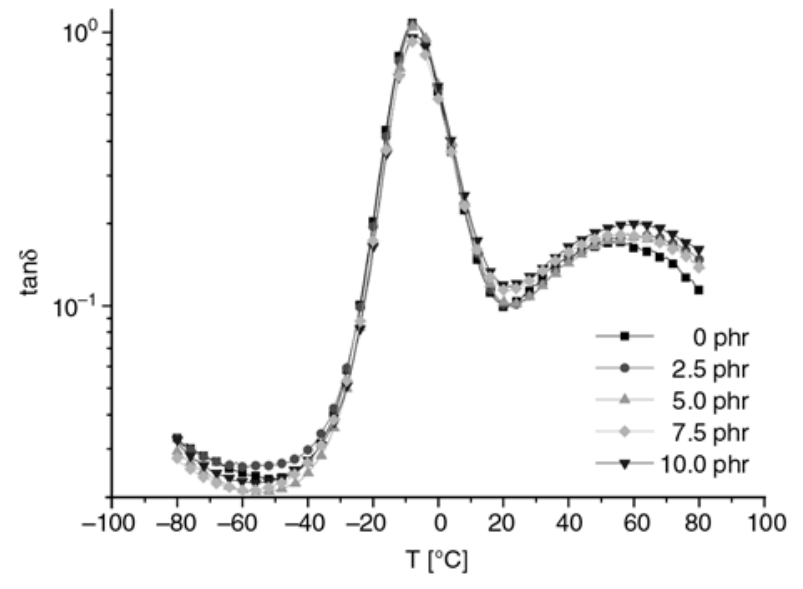

Figure 8. Representation of $\tan \delta$ vs. temperature of all investigated systems

the tan $\delta$ maximum decreases slightly with increasing filler content. An additional relaxation process at high temperatures is also confirmed in dynamicmechanical investigations but the difference between different amounts of organoclay are not as significant as in dielectric investigations. But like in dielectric measurements a shift to higher temperatures with incorporation of organoclay is detectable.

\subsection{TEM}

TEM pictures are able to give a direct impression about the distribution of nanoscale filler in the elastomer matrix. Figure 9 shows the sample filled with $5 \mathrm{phr}$ organoclay. Here the silicate layers in the rub-

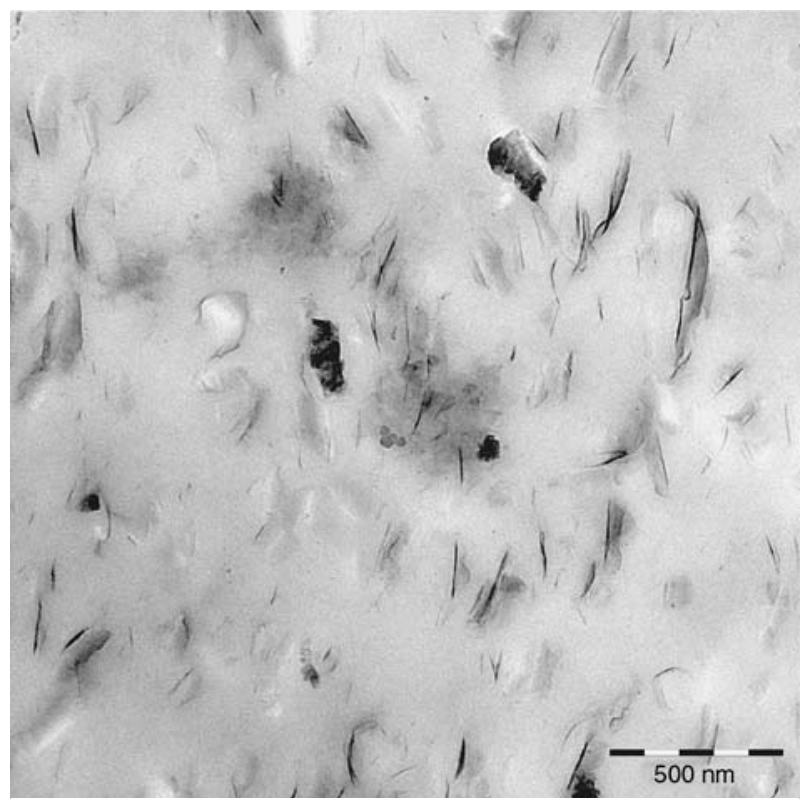

Figure 9. TEM picture of the XNBR sample filled with $5 \mathrm{phr}$ of Organoclay ber matrix are oriented preferably during the processing. A closer look gives the simultaneous existence of intercalated and exfoliated structures but as well there are still a few agglomerates of staged silicate layers so total exfoliation/intercalation is not achieved through melt processing.

\subsection{Discussion}

In literature the process at high temperatures is assigned to a formation of clusters due to the presence of $\mathrm{ZnO}$ and carboxylic groups [9-12]. This assumption was proven by IR-spectroscopic studies by Mandal [9] where characteristic peaks for Zncarboxyle-complexes have been be detected. The results of our IR-investigation are presented in Figure 10 and confirmed the interpretation given in literature.

The IR spectra show two strong peaks around 2925 and $2854 \mathrm{~cm}^{-1}$ due to the presence of $\mathrm{CH}_{2}$-groups. Another strong peak around $2237 \mathrm{~cm}^{-1}$ is due to the $\mathrm{CN}$-group in the acrylonitrile component. The important part of the spectrum is the range between 1500 and $1700 \mathrm{~cm}^{-1}$, where peaks due to the carboxylic part are responsible for effects of $\mathrm{C}=\mathrm{O}$ in different chemical environment. There is one peak at $1734 \mathrm{~cm}^{-1}$ due to the transesterfication of the monomeric carboxylic acid group. The peak at $1586 \mathrm{~cm}^{-1}$ was assigned to carbonyl stretching vibration of zinc carboxylate salt, the peak at $1540 \mathrm{~cm}^{-1}$ can be assigned to the hexacoordinated zinc carboxylate multiplet.

The infrared spectra for unfilled and filled specimen do not show a significant difference in the range between 1500 and $1700 \mathrm{~cm}^{-1}$. Accordingly, there seems to be no change of the chemical arrangement.

The high temperature peak of silica filled XNBR has been studied by Mandal et al. [10] using dynamic-mechanical measurements. Here, the increase of the relaxation process at high temperatures is accompanied by a shift of the relaxation process to higher temperatures with increasing silica loading. It is assumed that the increase of $\tan \delta$ in the high temperature relaxation process is due to the interaction of filler particles with the rubber chains in the cluster region.

In our dielectric measurements this interpretation agrees with the increase of the high-temperature relaxation process with increasing amount of 


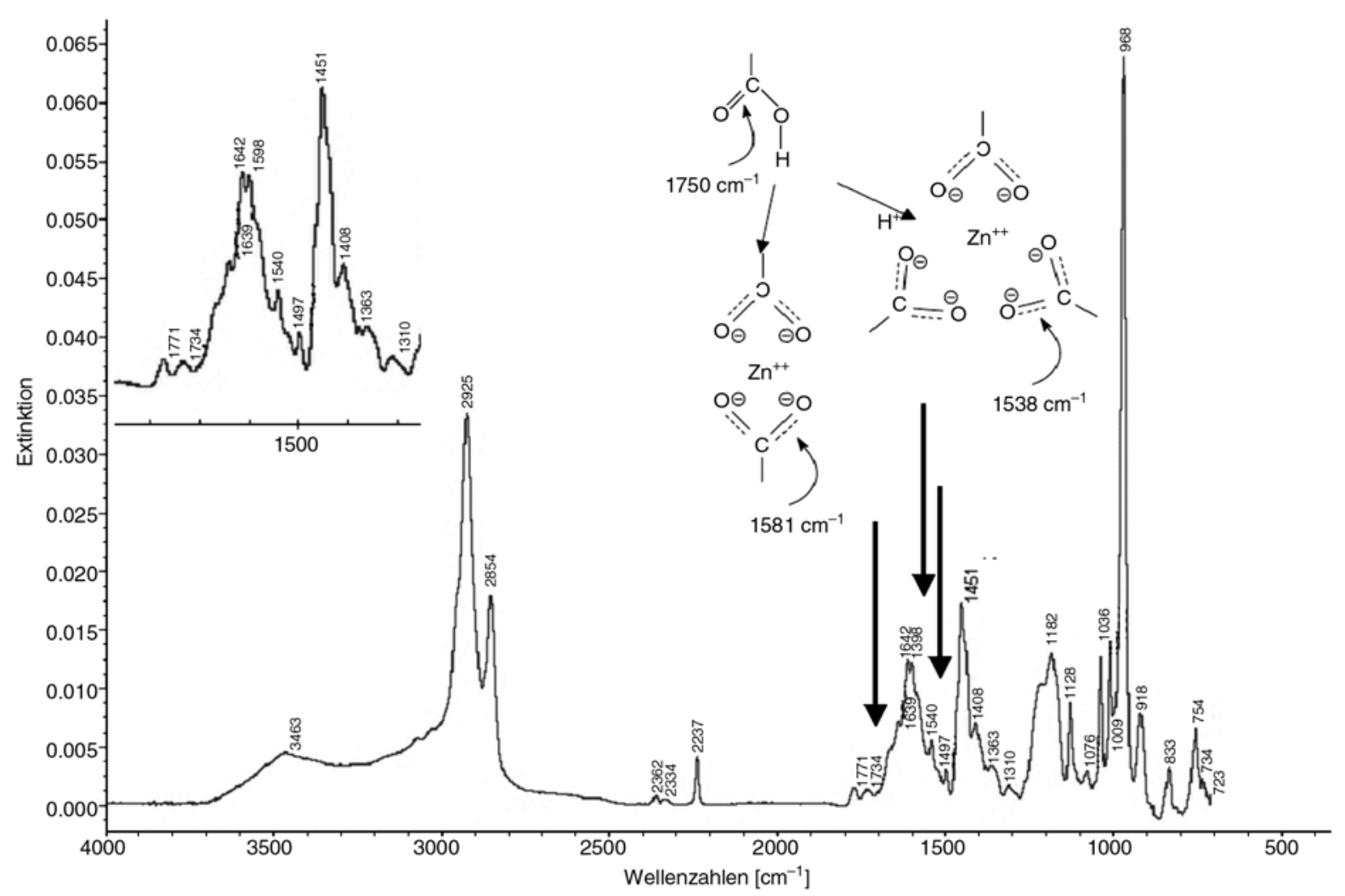

Figure 10. IR-spectrum of the unfilled XNBR sample

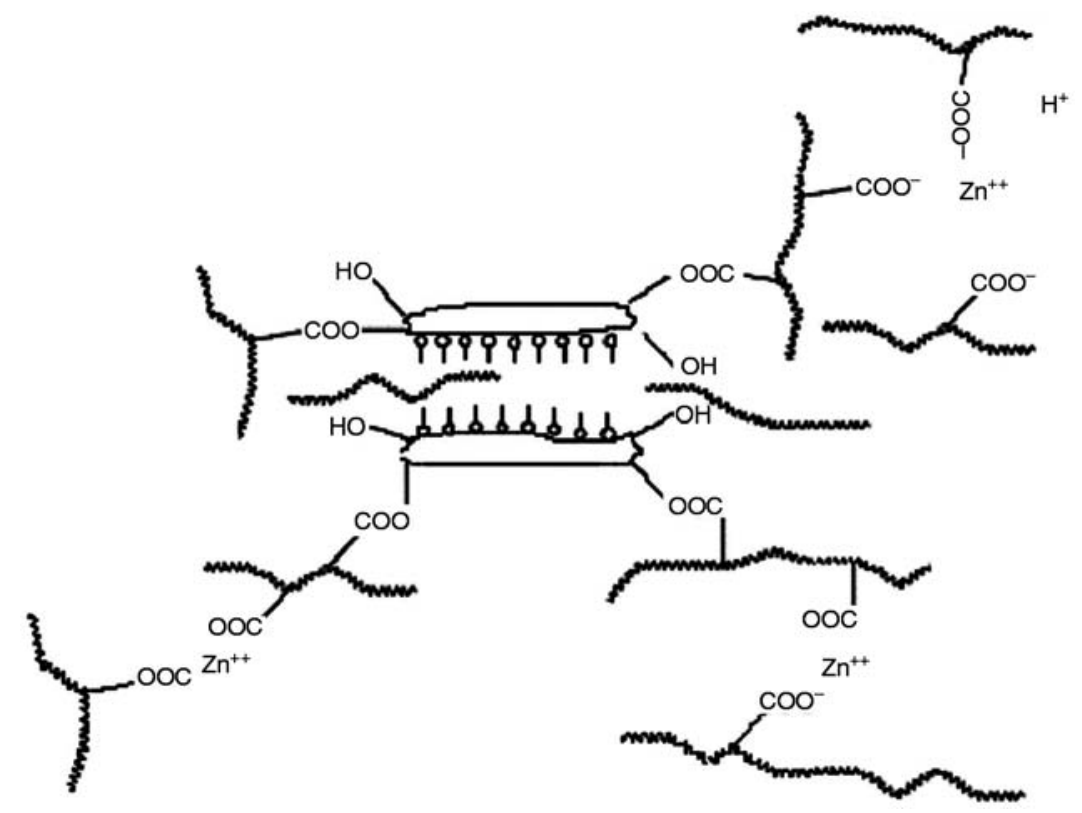

Figure 11. Model of reinforcement of organoclay in XNBR

organoclay and with the shift to higher temperatures. As well, the increase of the activation energy with the incorporation of organoclay seems to support the interpretation given in literature of a reinforcement in the cluster region. In that case the incorporation of layered silicate stabilizes the $\mathrm{Zn}$ carboxyle clusters resulting in the observed effects.
This can be the case when a direct bond between the layered silicate and the $\mathrm{Zn}$-Clusters is formed. A possible mechanism of $\mathrm{Zn}$-Cluster-reinforcement is shown in Figure 11. In that case the relaxation process at high temperatures in the filled samples is interpreted as a modification of the Zn-clusterbased process detected in the unfilled sample. 
As mentioned above the very small difference in activation energy of the high-temperature process among the different filled samples is conspicuous. With the underlying mechanism mentioned in Figure 11 one would expect an increasing activation energy with increasing organoclay loading. As well, the dynamic-mechanical data do not show the significant shift to higher temperatures as described in the literature for silica filled XNBR.

It is also possible to interpret the process in the filled samples as a separate filler based process which overlaps the process in the unfilled sample. A different process would explain the different activation energy of $15 \mathrm{~kJ} / \mathrm{mol}$ observed in the filled samples independent of filler content and also the apparently different location of the high temperature peaks for filled and unfilled samples as shown in Figure 3. In the frame of this interpretation the high temperature peak of the filled samples results from the glass transition of the immobilized polymer layer around the filler particles, which is more precisely a glass transition gradient near the filler surface due to attractive polymer-filler interaction [13] as described by several authors.

It was shown that the mobility of chain units adjacent to the filler surface differs considerably from the bulk resulting in an individual glass transition temperature of the interphase [14-16]. Hereby, the influence of this interphase on the macroscopic properties of the sample increases with the amount of filler. These effects are far from being well understood on a microscopic level due to the complex interplay between bulk and interphase. The specific glass transition temperature of the interphase usually lies several degrees above the glass transition temperature of the bulk due to the attractive polymer-filler forces. As well the VogelFulcher-Tamman activation behaviour and the value of the activation energy are not differ significantly from the value of the main glass transition process.

\section{Conclusions}

In this study the reinforcement effects of organoclay in XNBR have been investigated using dielectric and dynamic-mechanical analysis. Dielectric measurements as well as dynamic-mechanical studies suggest the formation of ionic clusters due to the presence of $\mathrm{ZnO}$. Infrared studies confirmed these assumptions, where peaks due to zinc carboxylate salts or multiplets have been detected. Measurements of dynamic-mechanical properties show only small reinforcement effects in areas away from the cluster region, in the cluster region itself a strong effect is detectable with dielectric measurements. Further investigations dealing with nano-silica [17] and with different kinds of organoclay as filler in XNBR are deemed to be necessary to have a clear understanding about concept and mechanism of elastomer reinforcement by nanoparticles.

\section{Acknowledgements}

This work has been supported by the German Federal Ministry of Education and Research (BMBF Grant 03X0002D). Helpful discussions with W. Herrmann (ContiTech AG, Hannover, Germany), C. Schmidt and C. Recker (both Continental AG, Hannover, Germany) and T. Engelhardt (Südchemie AG, Moosburg, Germany) are appreciated.

\section{References}

[1] Herrmann W., Uhl C., Heinrich G., Jehnichen D.: Analysis of HNBR-montmorillonite nanocomposites. Morphology, orientation and macroscopic properties. Polymer Bulletin, 57, 395-405 (2006).

[2] Ganter M., Gronski W., Reichert P., Mülhaupt R.: Rubber nanocomposites: Morphology and mechanical properties of BR and SBR vulcanizates reinforced by organophilic layered silicates. Rubber Chemistry and Technology, 74, 221-235 (2001).

[3] Tsuruk V. V.: Nanocomposite polymer layer for molecular tribology. Tribology Letters, 10, 127-132 (2001).

[4] Wang S., Zhang Y., Peng Z., Zhang Y.: New method for preparing polybutadiene rubber/clay composites. Journal of Applied Polymer Science, 98, 227-237 (2005).

[5] Li W., Huang Y. D., Ahmadi S. J.: Preparation and properties of ethylene-propylene-diene rubber/ organomontmorillonite nanocomposites. Journal of Applied Polymer Science, 94, 440-445 (2004).

[6] Das A., Jurk R., Stöckelhuber K. W., Engelhardt T., Fritzsche J., Klüppel M., Heinrich G.: Nanoalloy based on clays: Intercalated-exfoliated layered silicate in high performance elastomer. Journal of Macromolecular Science, Part A: Pure and Applied Chemistry, 45, 144-150 (2008).

[7] Steeman P. A. M., van Turnhout J.: A numerical Kramers-Kronig transform for the calculation of dielectric relaxation losses free from ohmic conduction losses. Colloid and Polymer Science, 275, 106-115 (1997). 
[8] Wübbenhorst M., van Turnhout J.: 'Conduction-free' dielectric loss $\sigma \varepsilon / \sigma \ln f-$ A powerful tool for the analysis of strong (ion) conducting dielectric materials. Dielectrics Newsletters, 14, 1-3 (2000).

[9] Mandal U. K.: Ionic elastomer based on carboxylated nitrile rubber: Infrared spectral analysis. Polymer International, 49, 1653-1657 (2000).

[10] Mandal U. K., Tripathy D. K., De S. K.: Effect of silica filler on dynamic mechanical properties of ionic elastomer based on carboxylated nitrile rubber. Journal of Applied Polymer Science, 55, 1185-1191 (1995).

[11] Ibarra L., Marcos-Fernández A., Alzorriz M.: Mechanistic approach to the curing of carboxylated nitrile rubber (XNBR) by zinc peroxide/zinc oxide. Polymer, 43, 1649-1655 (2002).

[12] Mahaling R. N., Jana G. K., Das C. K., Jeong H., Ha C. S.: Carboxylated nitrile elastomer/filler nanocomposite: Effect of silica nanofiller on thermal, dynamicmechanical behaviour and interfacial adhesion. Macromolecular Research, 13, 306-313 (2005).
[13] Berriot J., Montes H., Lequeux F., Long D., Sotta P.: Evidence for the shift of the galss transition near the particles in silica-filled elastomers. Macromolecules, 35, 9756-9762 (2002).

[14] Soles C. R., Douglas J. F., Wu W-L.: Dynamics of thin polymer films: Recent insights from incoherent neutron scattering. Journal of Polymer Science, Part B: Polymer Physics, 42, 3218-3234 (2004).

[15] Gagliardi S., Arrighi V., Ferguson R., Telling M. T. F.: Restricted dynamics in polymer-filler systems. Physica B, 301, 110-114 (2001).

[16] Anastasiadis S. H., Karatasos K., Vlachos G., Manias E., Giannelis E. P.: Nanoscopic-confinement effects on local dynamics. Physcal Review Letters, 84, 915918 (2000).

[17] Das A., Jurk R., Stöckelhuber K. W., Majumder P., Engelhardt T., Fritzsche J., Klüppel M., Heinrich G.: Nanocomposites based on layered silicate and carboxylated nitrile rubber: Effect of type of processing on the reinforcement. Polymer Engineering and Science, in press, (2008). 